\title{
A novel tumor suppressor gene NCOA5 is correlated with progression in papillary thyroid carcinoma
}

This article was published in the following Dove Press journal:

OncoTargets and Therapy

\section{Zhou-Ci Zheng* \\ Qing-Xuan Wang* \\ Wei Zhang \\ Xiao-Hua Zhang \\ Du-Ping Huang}

Department of Thyroid and

Breast Surgery, The First Affiliated

Hospital of Wenzhou Medical

University, Wenzhou, Zhejiang,

People's Republic of China

*These authors contributed equally to this work
Correspondence: Du-Ping Huang Department of Thyroid and Breast Surgery, The First Affiliated Hospital of Wenzhou Medical University, Nanbaixiang Street, Wenzhou, Zhejiang 325000, People's Republic of China $\mathrm{Tel} / \mathrm{fax}+8657755579462$

Email hdp_oncology@yeah.net
Background: In contrast to the excellent prognosis for papillary thyroid carcinoma (PTC), the high incidence of lymph node metastasis (LNM) markedly increases the risk of recurrence and secondary surgery. Thus, novel biomarkers must be urgently identified to assess LNM for patients with PTC. NCOA5 is deeply involved in the progression of human cancer; however, its role in thyroid cancer remains unknown.

Patients and methods: Quantitative real-time polymerase chain reaction was conducted to investigate the expression of NCOA5 in PTC. RNA-seq data from The Cancer Genome Atlas (TCGA) database were downloaded to further understand the role of NCOA5 in PTC and its relationship with LNM.

Results: NCOA5 was significantly downregulated in PTC tissues when compared with that in adjacent noncancerous thyroid tissues both in our local cohort and TCGA database. Reduced expression of NCOA5 was significantly associated with aggressive clinicopathological features, including histological type, tumor stage, BRAF-V600E mutation, LNM, extrathyroid extension, and clinical stage. Moreover, logistic analysis indicated that reduced expression of NCOA5, age, histological type, and clinical stage are independent high-risk factors for LNM in PTC.

Conclusion: Our study provides new insights and evidence that NOCA5 was significantly correlated with the progression of PTC and was particularly involved in LNM.

Keywords: thyroid cancer, NCOA5, lymph node metastasis

\section{Introduction}

Thyroid cancer is a common cancer worldwide ${ }^{1}$ and the most common malignant tumor of the endocrine system. ${ }^{2}$ Approximately 90,000 new cases and 6,800 deaths from this cancer occurred in China in $2015 .^{3}$ In addition, the incidence of thyroid cancer has increased at a markedly higher rate than that of any other cancer types. ${ }^{4-6}$ Papillary thyroid carcinoma (PTC) is the most common type of thyroid cancer and accounts for $>80 \%$ of all thyroid cancer cases. ${ }^{7}$

Patients with PTC have satisfactory prognosis after surgical and radio-iodinated therapy and an overall 10-year survival rate exceeding $90 \% .{ }^{8}$ A portion of PTC patients still exhibit poor prognosis, leading to disease recurrence and even death. ${ }^{9}$ Lymph node metastasis (LNM) is a major factor of locoregional recurrence and a distinct risk factor of mortality. ${ }^{10-12}$ Despite the excellent prognosis, the incidence of LNM is high and ranges from $20 \%$ to $50 \%,{ }^{13,14}$ leading to non-negligible possibilities of locoregional recurrence and secondary surgery. ${ }^{15-17}$

Although previous studies have identified several molecular markers associated with LNM, such as BRAF, ${ }^{18,19}$ TERT, ${ }^{20,21}$ and PIK3CA, ${ }^{22,23}$ much still remain (c)
hereby accept the Terms. Non-commercial uses of the work are permitted without any further permission from Dove Medical Press Limited, provided the work is properly attributed. For permission hereby accept the Terms. Non-commercial uses of the work are permitted without any further permission from Dove Medic
for commercial use of this work, please see paragraphs 4.2 and 5 of our Terms (https://www.dovepress.com/terms.php). 
unknown and require further study. In the present study, we reported that nuclear receptor coactivator 5 (NCOA5) was significantly related to LNM in PTC. NCOA5 was initially identified as a unique coactivator that is independent of AF2 and can modulate ER $\alpha$-mediated transcription. ${ }^{24,25}$ NCOA5 was reported to owning coactivator and corepressor functions, which could modulate ER $\alpha$-mediated transcription. ${ }^{24-26}$ NCOA5 is also deeply involved in the progression of several kinds of human cancer, including luminal breast cancer, ${ }^{27}$ esophageal squamous cell carcinoma, ${ }^{28}$ and hepatocellular carcinoma. $^{29,30}$ On the contrary, the role of NCOA5 in thyroid cancer remains unknown. In this study, we aimed to investigate the correlation between NCOA5 expression and the clinicopathological features of PTC using large-scale samples. In addition, the relationship between NCOA5 expression and LNM in PTC was further assessed by logistic regression analysis.

\section{Patients and methods}

\section{Patients and samples}

Seventeen paired PTC tissues and matched noncancerous thyroid tissues were resected during surgery. Tissue samples were snap-frozen in liquid nitrogen immediately after resection and then stored at $-80^{\circ} \mathrm{C}$ for subsequent RNA extraction. All the samples were reviewed retrospectively by two pathologists to confirm histological diagnosis. The study protocol and acquisition of tissue specimens used in this study were approved by the Ethics Committee of the First Affiliated Hospital of Wenzhou Medical University, and written informed consent for the scientific use of tissue samples was obtained from each patient.

\section{RNA extraction and quantitative real-time polymerase chain reaction ( $q R T-P C R$ )}

Total RNA of 17 samples was isolated using TRIzol reagent according to the manufacturer's protocol (Thermo Fisher Scientific, Waltham, MA, USA). RNA purity and concentration were detected by NanoDrop 2000 (Thermo Fisher Scientific). cDNA was prepared using the ReverTra Ace qPCR RT Kit (Toyobo, Osaka, Japan). qRT-PCR analysis of NOCA5 expression was conducted in triplicate using the THUNDERBIRD SYBR qPCR Mix (Toyobo) on the Roche 480 System (Hoffman-La Roche Ltd., Basel, Switzerland). The expression of GAPDH was used as an internal control. The primer sequences for NOCA5 are as follows: 5'-CAGTCAGCAGCAGTTACC-3' (forward) and 5'-CAGAGTCTCAGAACCAACTT-3' (reverse).
The Cancer Genome Atlas (TCGA) data

RNA-seq data of NCOA5 gene for PTC and corresponding clinical information, including total 503 PTC samples and 59 noncancerous thyroid tissues, were downloaded from TCGA database.

\section{Statistical analysis}

Data on normal distribution were evaluated by Student's $t$-test. Clinicopathological characteristics were compared by chi-square test. Univariate and multivariate logistic regression analyses were conducted to assess the relationship between NCOA5 expression and LNM in PTC. All $P$-values were two sided, and a $P$-value of 0.05 was considered statistically significant. Statistical analyses were performed using SPSS Version 22.0 (IBM Corporation, Armonk, NY, USA) and GraphPad Prism Version 6.01 (GraphPad Software, Inc., La Jolla, CA, USA).

\section{Results \\ NCOA5 was significantly downregulated in PTC}

To investigate the role of NCOA5 in PTC, we first assessed the mRNA expression of NOCA5 in 17 paired PTC tissues and adjacent noncancerous thyroid tissues by qRT-PCR analysis. Results showed that NOCA5 expression was significantly downregulated in PTC tissues compared with that in the adjacent noncancerous thyroid tissues $(P<0.001$, Figure 1$)$. RNA-seq data of NCOA5 gene for PTC from 503 PTC samples and 59 noncancerous thyroid tissues were downloaded from TCGA database to further confirm this finding. Accordingly, NCOA5 was significantly downregulated in

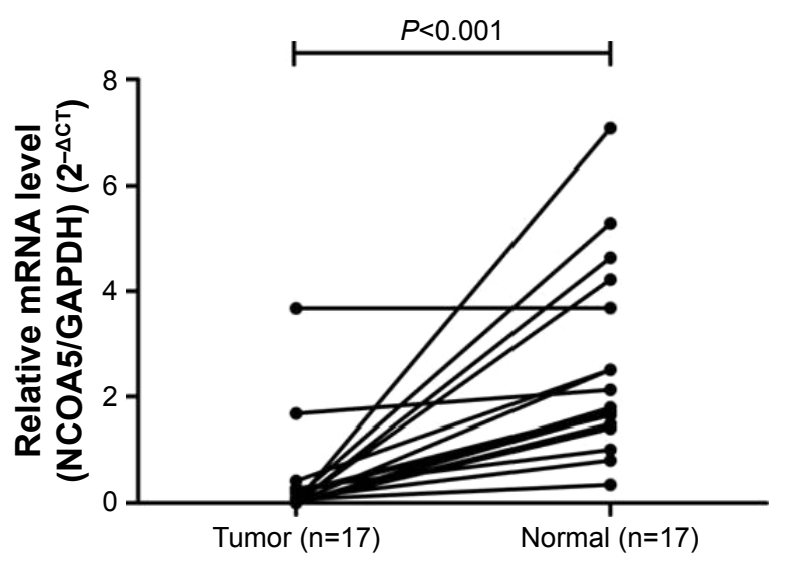

Figure I The mRNA expression of NCOA5 in our local cohort $(n=17)$. Note: NOCA5 expression was significantly downregulated in PTC tissues compared with the adjacent noncancerous thyroid tissues using qRT-PCR $(P<0.00 \mathrm{I})$.

Abbreviations: CT, cycle threshold; PTC, papillary thyroid carcinoma; qRT-PCR, quantitative real-time polymerase chain reaction. 


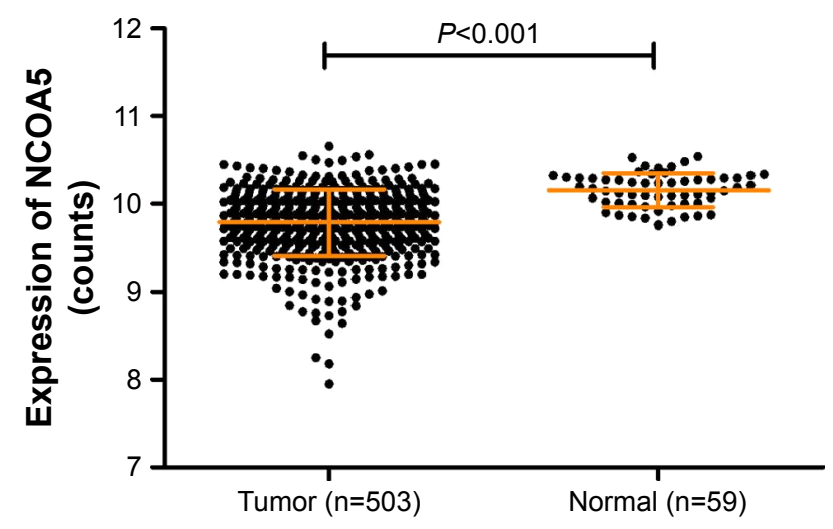

Figure 2 The mRNA expression of NCOA5 in TCGA cohort, including 503 PTC samples and 59 adjacent noncancerous thyroid samples.

Note: NOCA5 expression was also significantly downregulated in PTC in TCGA cohort $(P<0.001)$.

Abbreviations: PTC, papillary thyroid carcinoma; TCGA, The Cancer Genome Atlas.

PTC based on TCGA database $(P<0.001$, Figure 2$)$. This result indicated that NCOA5 may act as a tumor suppressor gene in PTC.

\section{NCOA5 expression and its relationship with the clinicopathological features in PTC}

To determine the involvement of NCOA5 in the progression of PTC, we investigated the relationship between NCOA5 expression and clinicopathological features. We categorized the 503 patients with PTC into low NOCA5 expression $(\mathrm{n}=251)$ and high NOCA5 expression $(\mathrm{n}=252)$ groups according to the median value. As shown in Table 1, the decreased expression of NCOA5 was associated with histological type $(P<0.001)$, BRAF-V600E mutation $(P<0.001)$, advanced tumor stage $(P=0.001)$, serious LNM $(P<0.001)$, extrathyroid extension $(P<0.001)$, and advanced clinical stage $(P=0.034)$. High expression of NCOA5 was inclined to classical and follicular subtype, whereas low expression of NCOA5 was inclined to tall cell subtype $(P<0.001$, Table 1$)$. However, the two groups were not significantly different in terms of age, gender, and multifocality $(P>0.05)$. All of these results supported NCOA5 to be a tumor suppressor gene in PTC.

\section{Low NCOA5 expression is correlated with high risk of LNM in PTC}

The relationship between NCOA5 expression and LNM was further assessed by logistic regression analysis. Univariate logistic regression analysis showed that age Odds ratio $(\mathrm{OR}=0.614$, 95\% CI $=0.424-0.891, P=0.010)$, gender $(\mathrm{OR}=1.541$,
Table I The relationship between NCOA5 expression and clinicopathological features in the TCGA cohort

\begin{tabular}{|c|c|c|c|}
\hline $\begin{array}{l}\text { Clinicopathological } \\
\text { features }\end{array}$ & $\begin{array}{l}\text { Low } \\
\text { expression } \\
(n=251)(\%)\end{array}$ & $\begin{array}{l}\text { High } \\
\text { expression } \\
(n=252)(\%)\end{array}$ & $P$-value \\
\hline \multicolumn{4}{|l|}{ Age (years) } \\
\hline Mean & $47.58 \pm 15.80$ & $46.87 \pm 15.90$ & 0.653 \\
\hline$>45$ & 131 (52.2) & $133(52.8)$ & 0.895 \\
\hline$\leq 45$ & $120(47.8)$ & $119(47.2)$ & \\
\hline Gender & & & 0.498 \\
\hline Male & $64(25.5)$ & 71 (28.2) & \\
\hline Female & $187(74.5)$ & |8| (7I.8) & \\
\hline Histological type & & & $<0.001$ \\
\hline Classical & $172(68.5)$ & $184(73.0)$ & \\
\hline Follicular & $40(15.9)$ & $60(23.8)$ & \\
\hline Tall & $33(13.1)$ & $3(1.2)$ & \\
\hline BRAF-V600E mutation & & & $<0.001$ \\
\hline Yes & |4| (56.2) & $94(37.3)$ & \\
\hline No & $102(40.6)$ & $153(60.7)$ & \\
\hline Tumor stage & & & 0.001 \\
\hline I & $60(23.9)$ & $82(32.5)$ & \\
\hline ॥ & $74(29.5)$ & $93(36.9)$ & \\
\hline III & $100(39.8)$ & $69(27.4)$ & \\
\hline IV & $17(6.8)$ & $6(2.4)$ & \\
\hline Lymph nodes metastasis & & & $<0.001$ \\
\hline Yes & $132(52.6)$ & $92(36.5)$ & \\
\hline No & $94(37.5)$ & $135(53.6)$ & \\
\hline Extrathyroid extension & & & $<0.001$ \\
\hline Yes & $96(38.2)$ & $56(22.2)$ & \\
\hline No & $146(58.2)$ & $187(74.2)$ & \\
\hline Multifocality & & & 0.077 \\
\hline Yes & $103(4 \mid .0)$ & $123(48.8)$ & \\
\hline No & $143(57.0)$ & $124(49.2)$ & \\
\hline Clinical stage & & & 0.034 \\
\hline$I+I I$ & $157(62.5)$ & $180(7 \mid .4)$ & \\
\hline III + IV & $93(37.1)$ & 7I (28.2) & \\
\hline
\end{tabular}

Abbreviation: TCGA, The Cancer Genome Atlas.

95\% CI $=1.016-2.337, P=0.042)$, histological subtype (OR=0.699, 95\% CI $=0.512-0.955, P=0.025)$, clinical stage $(\mathrm{OR}=1.598,95 \% \mathrm{CI}=1.340-1.907, P<0.001)$, extrathyroid extension $(\mathrm{OR}=2.876,95 \% \mathrm{CI}=1.892-4.372, P<0.001)$, BRAF-V600E mutation (OR=1.591, 95\% CI=1.092-2.317, $P=0.016)$, and NCOA5 expression $(\mathrm{OR}=0.485,95 \%$ $\mathrm{CI}=0.334-0.706, P<0.001)$ were significantly related to $\mathrm{LNM}$ (Table 2). Classical subtype was more inclined to LNM than to other subtypes. In addition, multivariate logistic regression analysis indicated that age $(\mathrm{OR}=0.026,95 \% \mathrm{CI}=0.009-0.079$, $P<0.001)$, histological subtype $(\mathrm{OR}=0.566,95 \% \mathrm{CI}=0.388$ $0.824, P=0.003)$, clinical stage $(\mathrm{OR}=6.246,95 \% \mathrm{CI}=3.683-$ 10.593, $P<0.001)$, and NCOA5 expression $(\mathrm{OR}=0.568,95 \%$ $\mathrm{CI}=0.356-0.908, P=0.018)$ were independent high-risk factors for LNM (Table 3). In summary, the low expression level of NCOA5 can aggravate the risk of LNM in PTC. 
Table 2 Univariate logistic regression analysis for the lymph node metastatic risk

\begin{tabular}{llll}
\hline $\begin{array}{l}\text { Clinicopathological } \\
\text { features }\end{array}$ & OR & $95 \% \mathbf{C l}$ & $P$-value \\
\hline Age & 0.614 & $0.424-0.89 I$ & 0.010 \\
Gender & 1.541 & $1.016-2.337$ & 0.042 \\
Histological type & 0.699 & $0.512-0.955$ & 0.025 \\
Clinical stage & 1.598 & $1.340-1.907$ & $<0.001$ \\
Multifocality & 1.381 & $0.950-2.008$ & 0.091 \\
Extrathyroid extension & 2.876 & $1.892-4.372$ & $<0.001$ \\
BRAF-V600E mutation & 1.591 & $1.092-2.317$ & 0.016 \\
NCOA5 expression & 0.485 & $0.334-0.706$ & $<0.001$ \\
\hline
\end{tabular}

Abbreviation: OR, Odds ratio.

\section{Discussion}

Thyroid cancer is the most common endocrine malignancy and one of the fastest growing types of human cancer. ${ }^{1,2}$ Although the prognosis of PTC is relatively favorable, the high incidence of LNM at $\sim 20 \%-50 \%,{ }^{13,14}$ increases the possibility of locoregional recurrence and secondary surgery. ${ }^{15-17}$ To date, effective indicators that accurately evaluate lymph node status remain lacking.

In this study, we first reported a gene named NCOA5, which was significantly involved in LNM of PTC. The mRNA expression of NOCA5 in PTC was first assessed by qRT-PCR. NOCA5 expression was significantly downregulated in PTC tissues compared with that in adjacent noncancerous thyroid tissues. This finding is further confirmed by the analysis of TCGA database with a large sample size. In addition, the decreased expression level of NCOA5 was significantly associated with aggressive clinicopathological features, such as serious LNM and advanced clinical stage. Logistic regression analysis showed that the low NOCA5 expression level was an independent high-risk factor for LNM in PTC, with an odds ratio value of 0.568. All these results confirm the role of NCOA5 as a tumor suppressor gene in PTC and its critical function in the progression of LNM.

Table 3 Multivariate logistic regression analysis for the lymph node metastatic risk

\begin{tabular}{llll}
\hline $\begin{array}{l}\text { Clinicopathological } \\
\text { features }\end{array}$ & OR & $\mathbf{9 5 \%} \mathbf{C l}$ & P-value \\
\hline Age & 0.026 & $0.009-0.079$ & $<0.001$ \\
Gender & 1.177 & $0.698-1.985$ & 0.540 \\
Histological type & 0.566 & $0.388-0.824$ & 0.003 \\
Clinical stage & 6.246 & $3.683-10.593$ & $<0.001$ \\
Extrathyroid extension & 1.420 & $0.843-2.391$ & 0.188 \\
BRAF-V600E mutation & 1.478 & $0.927-2.355$ & 0.101 \\
NCOA5 expression & 0.568 & $0.356-0.908$ & 0.018 \\
\hline
\end{tabular}

Abbreviation: OR, Odds ratio.
NCOA5 was initially identified as a unique coactivator that is independent of AF2 and can modulate ERa-mediated transcription. ${ }^{24,25}$ NCOA5 is also involved in several human diseases, including Behçet's disease, ${ }^{31}$ type 2 diabetes, ${ }^{32}$ and cholesterol metabolism. ${ }^{32}$ Recent studies have found that NCOA5 is significantly related to human cancer. Gao et al found that 18-month-old mice with haplo-insufficient NCOA5 can develop hepatocellular carcinoma. In addition, NCOA5 is significantly downregulated in human hepatocellular carcinoma ${ }^{29,33}$ and is involved in cell cycle regulation in hepatocellular carcinoma. ${ }^{30}$ Chen et al showed that the low expression level of NCOA5 is associated with the progression of esophageal squamous cell carcinoma and thus could be used to predict poor prognosis. ${ }^{28}$ However, in our previous study, NCOA5 was significantly upregulated in luminal breast cancer tissues compared with that in adjacent noncancerous tissues and the high NCOA5 expression is correlated with poor prognosis in luminal breast cancer. ${ }^{27}$ In the present study, NOCA5 expression was significantly downregulated in PTC. This finding is consistent with most studies concerning human cancer and indicated that NOCA5 plays different roles in different kinds of human cancer. The exact cellular mechanisms of NOCA5 must be further explored. To the best of our knowledge, our study is the first to present the significant role of NCOA5 in PTC.

Despite these inspiring findings, this work includes certain limitations. First, in vitro and in vivo experiments are further needed to reveal the biological effects of NCOA5 in PTC. Second, the specific mechanism of NCOA5 inhibiting LNM should be further studied.

\section{Conclusion}

NCOA5 was significantly downregulated in PTC. The low expression of NCOA5 is correlated with a high risk of LNM in PTC. NCOA5 may act as a promising tumor suppressor gene and is worthy of further study.

\section{Acknowledgments}

This study was supported by the Major Science and Technology Projects of Zhejiang Province (2015C03052) and Science Foundation from Health Bureau of Wenzhou City of Zhejiang, China (Y20160036).

\section{Disclosure}

The authors report no conflicts of interest in this work.

\section{References}

1. Siegel RL, Miller KD, Jemal A. Cancer Statistics, 2017. CA Cancer J Clin. 2017;67(1):7-30. 
2. Rahib L, Smith BD, Aizenberg R, Rosenzweig AB, Fleshman JM, Matrisian LM. Projecting cancer incidence and deaths to 2030: the unexpected burden of thyroid, liver, and pancreas cancers in the United States. Cancer Res. 2014;74(11):2913-2921.

3. Chen W, Zheng R, Baade PD, et al. Cancer statistics in China, 2015. CA Cancer J Clin. 2016;66(2):115-132.

4. Chen AY, Jemal A, Ward EM. Increasing incidence of differentiated thyroid cancer in the United States, 1988-2005. Cancer. 2009;115(16): 3801-3807.

5. Davies L, Welch HG. Current thyroid cancer trends in the United States. JAMA Otolaryngol Head Neck Surg. 2014;140(4):317-322.

6. Pellegriti G, Frasca F, Regalbuto C, Squatrito S, Vigneri R. Worldwide increasing incidence of thyroid cancer: update on epidemiology and risk factors. J Cancer Epidemiol. 2013;2013:965212.

7. Xing M. Molecular pathogenesis and mechanisms of thyroid cancer. Nat Rev Cancer. 2013;13(3):184-199.

8. Leboulleux S, Rubino C, Baudin E, et al. Prognostic factors for persistent or recurrent disease of papillary thyroid carcinoma with neck lymph node metastases and/or tumor extension beyond the thyroid capsule at initial diagnosis. J Clin Endocrinol Metab. 2005;90(10): 5723-5729.

9. Burns WR, Zeiger MA. Differentiated thyroid cancer. Semin Oncol. 2010;37(6):557-566

10. Kim SK, Kwon AY, Back K, et al. Predictive factors of lymph node metastasis in follicular variant of papillary thyroid carcinoma. Ann Surg Oncol. 2017;24(9):2617-2623.

11. Lundgren CI, Hall P, Dickman PW, Zedenius J. Clinically significant prognostic factors for differentiated thyroid carcinoma: a populationbased, nested case-control study. Cancer. 2006;106(3):524-531.

12. Zidan J, Karen D, Stein M, Rosenblatt E, Basher W, Kuten A. Pure versus follicular variant of papillary thyroid carcinoma: clinical features, prognostic factors, treatment, and survival. Cancer. 2003; 97(5):1181-1185.

13. Mustafa M, Kuwert T, Weber K, et al. Regional lymph node involvement in T1 papillary thyroid carcinoma: a bicentric prospective SPECT/ CT study. Eur J Nucl Med Mol Imaging. 2010;37(8):1462-1466.

14. Schneider DF, Chen H. New developments in the diagnosis and treatment of thyroid cancer. CA Cancer J Clin. 2013;63(6):374-394.

15. Lee YC, Na SY, Park GC, Han JH, Kim SW, Eun YG. Occult lymph node metastasis and risk of regional recurrence in papillary thyroid cancer after bilateral prophylactic central neck dissection: a multiinstitutional study. Surgery. 2017;161(2):465-471.

16. Lee YM, Sung TY, Kim WB, Chung KW, Yoon JH, Hong SJ. Risk factors for recurrence in patients with papillary thyroid carcinoma undergoing modified radical neck dissection. Br J Surg. 2016;103(8):1020-1025.

17. Liu FH, Kuo SF, Hsueh C, Chao TC, Lin JD. Postoperative recurrence of papillary thyroid carcinoma with lymph node metastasis. J Surg Oncol. 2015;112(2):149-154.
18. Nikiforov YE, Nikiforova MN. Molecular genetics and diagnosis of thyroid cancer. Nat Rev Endocrinol. 2011;7(10):569-580.

19. Xing M. BRAF mutation in thyroid cancer. Endocr Relat Cancer. $2005 ; 12(2): 245-262$.

20. Liu X, Qu S, Liu R, et al. TERT promoter mutations and their association with BRAF V600E mutation and aggressive clinicopathological characteristics of thyroid cancer. J Clin Endocrinol Metab. 2014; 99(6):E1130-E1136.

21. Xing M, Liu R, Liu X, et al. BRAF V600E and TERT promoter mutations cooperatively identify the most aggressive papillary thyroid cancer with highest recurrence. J Clin Oncol. 2014;32(25):2718-2726.

22. Garcia-Rostan G, Costa AM, Pereira-Castro I, et al. Mutation of the PIK3CA gene in anaplastic thyroid cancer. Cancer Res. 2005;65(22): 10199-10207.

23. Hou P, Liu D, Shan Y, et al. Genetic alterations and their relationship in the phosphatidylinositol 3-kinase/Akt pathway in thyroid cancer. Clin Cancer Res. 2007;13(4):1161-1170.

24. Jiang C, Ito M, Piening V, Bruck K, Roeder RG, Xiao H. TIP30 interacts with an estrogen receptor alpha-interacting coactivator CIA and regulates c-myc transcription. J Biol Chem. 2004;279(26):27781-27789.

25. Sauve F, McBroom LD, Gallant J, Moraitis AN, Labrie F, Giguere V. CIA, a novel estrogen receptor coactivator with a bifunctional nuclear receptor interacting determinant. Mol Cell Biol. 2001;21(1):343-353.

26. Zhang Z, Teng CT. Estrogen receptor alpha and estrogen receptorrelated receptor alpha1 compete for binding and coactivator. Mol Cell Endocrinol. 2001;172(1-2):223-233.

27. Ye XH, Huang DP, Luo RC. NCOA5 is correlated with progression and prognosis in luminal breast cancer. Biochem Biophys Res Commun. 2017;482(2):253-256

28. Chen GQ, Tian H, Yue WM, et al. NCOA5 low expression correlates with survival in esophageal squamous cell carcinoma. Med Oncol. 2014;31(12):376.

29. Gao S, Li A, Liu F, et al. NCOA5 haploinsufficiency results in glucose intolerance and subsequent hepatocellular carcinoma. Cancer Cell. 2013;24(6):725-737.

30. Liu X, Liu F, Gao S, et al. A single non-synonymous NCOA5 variation in type 2 diabetic patients with hepatocellular carcinoma impairs the function of NCOA5 in cell cycle regulation. Cancer Lett. 2017;391: $152-161$.

31. Rustemoglu A, Erkol Inal E, Inanir A, et al. Clinical significance of NCOA5 gene rs2903908 polymorphism in Behcet's disease. EXCLIJ. 2017;16:609-617.

32. Gillespie MA, Gold ES, Ramsey SA, Podolsky I, Aderem A, Ranish JA. An LXR-NCOA5 gene regulatory complex directs inflammatory crosstalk-dependent repression of macrophage cholesterol efflux. EMBO J. 2015;34(9):1244-1258.

33. Dhar D, Seki E, Karin M. NCOA5, IL-6, type 2 diabetes, and HCC: the deadly quartet. Cell Metab. 2014;19(1):6-7.
OncoTargets and Therapy

\section{Publish your work in this journal}

OncoTargets and Therapy is an international, peer-reviewed, open access journal focusing on the pathological basis of all cancers, potential targets for therapy and treatment protocols employed to improve the management of cancer patients. The journal also focuses on the impact of management programs and new therapeutic agents and protocols on

\section{Dovepress}

patient perspectives such as quality of life, adherence and satisfaction. The manuscript management system is completely online and includes a very quick and fair peer-review system, which is all easy to use. Visit http://www.dovepress.com/testimonials.php to read real quotes from published authors. 